\title{
POSIBILIDADES Y LIMITACIONES DE LA PARTICIPACION JUVENIL PARA EL IMPACTO EN LA AGENDA PUBLICA: El caso del Consejo Municipal de Juventud en Medellín*
}

\author{
MigUEL ABAD**
}

\section{INTRODUCCIÓN}

NO SIENDO EXPERTO EN ciencias políticas, necesariamente mi presentación estará más centrada en exponer unas reflexiones elementales que pueden hacerse a cargo del sentido común, admitiendo las virtudes propias de sus defectos, y efectuada a partir de una experiencia de trabajo concreta, la de Paisajoven, vinculada en general con los temas de la participación ciudadana de los jóvenes, y en particular, con el caso del Consejo Municipal de Juventud de Medellín (CMJ).

Si bien lo anterior no me exonera de ninguna responsabilidad de «autor», la advertencia pretende conseguir que los lectores atemperen sus expectativas y se dispongan más bien a ocuparse de la tarea, con toda seguridad más ardua, de mejorar por su cuenta las interpretaciones teóricas apenas insinuadas por estas reflexiones.

* $\quad$ Presentación realizada en el foro «Estrategias para la participación ciudadana y comunitaria en Colombia», organizado por el Ministerio del Interior, la Universidad Pontificia Javeriana y la Universidad de Georgetown, en Bogotá, marzo del 2001.

** Psicólogo argentino, coordinador Área de Organización Juvenil de la Corporación Paisajoven, Medellín. E-Mail: juventud@epm.net.co. 
En estas condiciones, y sin ningún afán de sentar cátedra, me creo obligado a establecer lo más precisa y tempranamente posible un punto de vista desde donde voy a mirar el «bosque», por llamarlo así, de la participación ciudadana. Como cualquier visión de conjunto, y no siendo propiamente mi área de trabajo, omitiré con toda seguridad cuestiones que son fundamentales y en cambio cometeré gruesos errores de apreciación, que les pido tengan la generosidad de disculpar y corregir.

Siendo así, pido excusas nuevamente por la muy probable superficialidad con la que abordaré temas en los que muchos de ustedes son especialistas, así que pasaré muy rápidamente a exponer algunas características que a mi modo de ver definen las posibilidades de la participación ciudadana de los jóvenes, tema en el cual me siento un poco sobre terreno conocido. Esta parte pretende establecer el contexto más amplio en que se desarrolla la experiencia del Consejo Municipal de Juventud en Medellín, y me parece un paso fundamental para argumentar mi lectura posterior sobre este caso concreto de participación ciudadana.

Para terminar, voy a procurar establecer alguna relación entre las condiciones que favorecen o limitan la participación ciudadana de los jóvenes con el caso particular del Consejo Municipal de Juventud de Medellín, procurando enfatizar en todo momento las lecciones aprendidas, para concluir con unas recomendaciones que, según opinión muy personal, podrían mejorar las posibilidades de esta experiencia que promueve la participación de los jóvenes.

Por supuesto que lo primero es proporcionar la información necesaria para que los lectores tengan una idea básica, si no la poseen, sobre el origen y evolución del Consejo Municipal de Juventud. Ahora bien, no quisiera que esperasen una descripción detallada de este organismo, sino únicamente la enumeración de los hechos más importantes y útiles al tema central de la presentación. De todas formas, existe más información que el propio Consejo Municipal de Juventud de Medellín está en condiciones de compartir con los interesados.

\section{INFORMACIÓN BÁSICA SOBRE EL CMJ DE MEDELLÍN}

El Consejo Municipal de Juventud es un organismo previsto en la Ley de Juventud (375/97) para cumplir una variedad de funciones, pero que básicamente son de interlocución con la Administración Municipal en los asuntos referidos a la juventud. Nacionalmente, el 
primer CMJ en Colombia se creó en Medellín mediante Acuerdo Municipal 07/94, es decir, tres años antes de que por Ley se establecieran para todos los municipios del país lo cual supone una mayor responsabilidad en la eficiencia de este mecanismo. Hasta ahora, han sido elegidos dos consejos en la ciudad: el primero en 1995 y el segundo en el 2000.

Bajo el acuerdo mencionado, el CMJ tenía esencialmente una función de «asesores y consultores» del alcalde en los temas relativos a las problemáticas juveniles de la ciudad, lo cual generó - tanto en el primero como en el segundo CMJ- expectativas de una cercanía a las instancias más altas del gobierno municipal, luego frustradas en la realidad. Aun así, el CMJ ha obtenido importantes lugares de representación en escenarios de concertación pública, como el Consejo Municipal de Planeación, el Consejo Municipal de Paz, la Corporación Paisajoven y la Red de Apoyo a la Política Pública Municipal de Juventud.

Durante estos años, a pesar de los logros mencionados, ha sido un organismo prácticamente desconocido por los jóvenes de la ciudad, $y$, hay que decirlo, ha enfrentado serios y bien fundados cuestionamientos desde las organizaciones no gubernamentales por la pertinencia y claridad de sus actuaciones. A menudo se le han atribuido prácticas clientelistas, especialmente al segundo, y se ha criticado su poca vinculación con las organizaciones juveniles, con las cuales predomina una relación de desconfianza y competencia con la organización que perciben como el «grupo juvenil» del municipio, a pesar que en la práctica la relación con el gobierno ha sido más por contactos personales de sus integrantes, que por vías formales e instituidas.

Está compuesto en la actualidad por 17 consejeros juveniles, quienes fueron elegidos por votación directa de los jóvenes de la ciudad con edades entre 14 y 26 años, siendo el primer Consejo de Juventud en el mundo conformado de esta manera. El 60\% de estos jóvenes son de candidaturas «independientes», en el sentido de que no fueron avalados por ninguna organización o movimiento juvenil, mientras el restante $40 \%$ representan a organizaciones juveniles o a sectores juveniles de organizaciones adultas.

A diferencia de la elecciones del primer CMJ, cuyos candidatos se presentaron bajo una circunscripción electoral determinada por las 16 comunas y los 5 corregimientos rurales de la ciudad, y eran votados por los jóvenes registrados como electores en estas mismas divisiones territoriales, los candidatos y actuales consejeros no están 
adscritos necesariamente a una comuna o corregimiento específico, sino que pueden ser votados por los jóvenes de cualquier sector de la ciudad, dependiendo obviamente de su campaña y capacidad para movilizar una opinión favorable.

La crisis económica que viene padeciendo el Municipio de Medellín ha incidido negativamente en el presupuesto asignado al CMJ, que ha disminuido hasta cero en este año, lo cual ha puesto a sus integrantes en el falso dilema de «pelear» unos recursos como condición para su funcionamiento, sin reflexionar adecuadamente sobre sus posibilidades de actuación ni realizar una valoración de sus necesidades reales ni hacer contactos con otras organizaciones que podrían facilitarle algunos medios para desarrollar unas actividades siquiera básicas: de alguna manera, al no tener un plan concreto, cualquier recurso puede ser demasiado o insuficiente...

En este momento, el CMJ está procurando salir de la crisis más seria que ha tenido en su corta vida, y empieza a relacionarse un poco más activamente con distintas organizaciones no gubernamentales, encontrando respaldo institucional y apoyo económico. Sin embargo, sigue manteniendo una actuación muy poco coordinada entre sus integrantes, a la vez que persisten crecientes niveles de ausentismo en sus reuniones internas y se demuestra escaso compromiso en el cumplimiento con convocatorias y en la respuesta a acuerdos con otras instituciones. Más recientemente se ha empezado a generar un creciente descontento ante su falta de participación en el proceso de la Política Pública Municipal de Juventud de Medellín.

$\mathrm{Al}$ analizar el conjunto de CMJ'S actualmente vigentes en el país, ${ }^{1}$ una mirada global permite afirmar unas debilidades comunes:

i) Inconvenientes en los procesos de electorales: falta de apoyo y vigilancia de la Registraduría Nacional; decretos y acuerdos municipales poco transpirantes e insuficientemente divulgados; denuncias de favoritismos en el apoyo a ciertos candidatos en detrimento de otros; desorganización en el funcionamiento de las mesas de inscripción para los votantes.

ii) Competencias y roles difusos: no hubo una distribución de tareas y responsabilidades entre organismos nacionales y mu-

1 Entre abril y noviembre de 2000, fueron elegidos 6 Consejos Municipales de Juventud en todo el país; el Programa Presidencial Colombia Joven ha planeado impulsar y apoyar las elecciones de CMJ's en 350 municipios hacia el final del 2001. 
nicipales, ni de éstas con organizaciones juveniles; funciones en competencia entre organismos de representación juvenil existentes en los municipios, Oficinas Municipales de Juventud y Consejos de Juventud recientemente elegidos.

iii) Problemas de representatividad y legitimidad: bajas votaciones de los candidatos; cuestionamiento de la legitimidad de los consejos elegidos por parte de las organizaciones juveniles; desconfianza sobre los resultados electorales.

\section{CIUDADANÍA, JUVENTUD Y MERCADO POLÍTICO}

Si entendemos, al menos en uno de sus múltiples aspectos, que la ciudadanía también se define por un conjunto de normas e instituciones que guían la relación pública entre el individuo, la sociedad y el Estado, en la ciudadanía moderna hay una tendencia a que estas normas e instituciones proporcionen herramientas que generen y hagan sostenible las condiciones que propicien una participación pública lo más equitativa posible por parte de los individuos que conforman la sociedad.

Un aspecto primordial en la ciudadanía moderna es la creciente diversidad de actores sociales con intereses particulares que pugnan por una mayor participación pública, la mayoría de las veces con énfasis distintos y hasta antagónicos, y que por distintos medios - no todos formalizados institucionalmente-, buscan cómo mejorar sus posiciones de influencia en la toma de decisiones de interés general sobre aspectos que los favorecen o perjudican.

En tal sentido, la participación ciudadana, en todas sus variadas dimensiones, no excluye entre sus características configurarse como una relación de poder y, por tanto, como una relación política, a través de la cual una pluralidad de actores sociales confrontan y disputan, con mayor o menor capacidad, sus posibilidades de influencia en decisiones sobre el acceso y uso de los recursos de poder disponibles (legales, económicos, etc.). Para pasar de una participación posible a una participación real, es decir, del potencial para influir en decisiones a la efectiva toma de decisiones, es necesario que el individuo tenga la voluntad para ejercer su ciudadanía, y que la sociedad le reconozca efectivamente ese derecho, facilitando espacios para ese ejercicio, informando y comunicando sobre las decisiones a tomar, y acordando reglas, para que todos, independientemente de sus condiciones individuales, puedan ejercer lo más equitativamente su derecho. 
Anteriormente teníamos formas de ciudadanía restringidas: se trataba de llevar la gente a la ciudadanía, en un esfuerzo por forjar una identidad nacional y mejorar así la gobernabilidad de las nacientes sociedades democráticas, bajo el juicio de que solamente un pequeño grupo estaba capacitado para elegir y ser elegido, con la aspiración de que el progreso económico y la educación irían conformando una ciudadanía más homogénea. Esto significaba, en la práctica, una serie de condiciones para limitar la participación a ciertos grupos, en momentos determinados y mediante mecanismos específicos.

Así, las primeras democracias establecidas en Gran Bretaña, Estados Unidos y Francia fueron esencialmente censitarias y masculinas, donde únicamente la burguesía tenía derechos de ciudadanía, y aun hoy, por ejemplo para las elecciones de cargos públicos, los electores deben ser mayores de edad y nacidos en el país aunque anteriormente, además, debían ser hombres, saber leer y escribir, y tener propiedades o una renta mínima.

Progresivamente, y de manera principal mediante la educación, en una paradójica inversión de efectos, distintas presiones de todo tipo han venido ampliando y diversificando la noción de ciudadanía para abarcar los terrenos más allá de la participación política formal e incluir a nuevos actores sociales, entre ellos a los jóvenes. Este nuevo sentido podría simplificarse como llevar la ciudadanía a la gente.

Existe pues una marcada tendencia a admitir formas de ciudadanía diferenciada, en un esfuerzo por publificar, es decir, de visualizar, incluir y reconocer en la escena pública, a nuevos actores sociales y nuevas formas de participación real, en lugar de pretender uniformar la forma de ser y hacer ciudadanía. Este es el caso de los jóvenes, como lo ha sido el de los obreros, las mujeres, los indígenas y los negros, por ejemplo.

Obviamente esta pretendida ciudadanía juvenil, como una forma diferente y particular de ser ciudadano, no se produce en el vacío, sino que está irremisiblemente atravesada por un complejo y dinámico entramado de relaciones entre poderes, con distintas posibilidades — según el momento - para movilizar recursos e influir en las decisiones colectivas sobre el interés general de la sociedad.

Es notorio que en esa relación entre poderes se produce un verdadero mercado político donde es patente que no se regala nada, pero justamente la diferencia que introduce un orden democrático es que, lejos de pretender someter este «mercado» a un solo poder para 
mantenerlo estático y siempre igual, procura aprovechar el conflicto entre diversos poderes, y aun la diferencias de fuerzas, para garantizar, aunque sea imperfectamente, una «anarquía organizada» en la cual los intereses particulares de los actores sociales están legitimados por derecho y no por fuerza para incidir en la dirección del interés general de la sociedad.

La tendencia de los órdenes democráticos es hacia procurar la mayor participación de intereses particulares en las decisiones colectivas de interés general, con el máximo grado de beneficio para los menos favorecidos y el menor perjuicio posible para todos, actuando bajo reglas y procedimientos acordados y procesos públicos, es decir, visibles. Admitiendo lo ideal de esta muy superficial descripción, el orden democrático será más perfecto en tanto promueva y garantice la libre participación y competencia de los intereses particulares, no solamente en un sentido negativo, es decir, que no se coaccione su necesaria autonomía, sino también desarrollando condiciones que hagan efectiva esa libertad.

Lo anterior significa que para su participación en las decisiones colectivas, los intereses particulares necesitan algo más que el reconocimiento de su libertad de expresión para ser tenidos en consideración, y es la oportunidad, la capacidad y la elección de influir como poder en las decisiones que los afectan. Ahí es donde toma sentido la necesidad de fortalecer y perfeccionar instituciones especiales como el Consejo Municipal de Juventud, así como apoyar a las organizaciones juveniles, para que los jóvenes aumenten su participación en el mercado político, algo que no solamente beneficiaría a los jóvenes, sino —y quizás en mayor medida — a la sociedad en su conjunto.

Ampliando esta afirmación, recurro a la hipótesis, nada original por otra parte, que los jóvenes hacen parte de unas tendencias emergentes y reformistas que en su conjunto están modernizando nuestras sociedades, y, por lo tanto, apoyar sus organizaciones y facilitarles medios de expresión y actuación, es apostar clara y decididamente a favor de estos cambios; inversamente, cualquier déficit de ciudadanía entre los jóvenes, desde los producidos por falta de educación o precaria inserción laboral, hasta los ocasionados por la debilidad del tejido organizacional juvenil que agrega y moviliza sus propias demandas e intereses, refuerzan las tendencias conservadoras de una sociedad a la cual, sin embargo, le urge el cambio. 


\begin{tabular}{|c|c|}
\hline TENDENCIAS REFORMISTAS & TENDENCIAS CONSERVACIONISTAS \\
\hline Pensamiento sistémico y complejo & Racionalismo \\
\hline Democracia liberal y comunitarista & Autoritarismos de izquierda o derecha \\
\hline Mercado / sociedad civil & Estado \\
\hline Tecnologías de la tercera ola & Tecnología de la segunda ola \\
\hline Ciudades & Naciones \\
\hline $\begin{array}{c}\text { Descentralización de poderes } \\
\text { y procedimientos }\end{array}$ & Burocracia y planificación central \\
\hline Nuevos movimientos sociales & Partidos políticos \\
\hline Perspectiva de género & Androcentrismo \\
\hline Jóvenes & Adultos \\
\hline
\end{tabular}

La confrontación entre poderes reformistas y conservadores no supone de entrada, y como es de fácil verificación en la realidad, la aniquilación de unos por otros; la mayoría de las veces, el complejo campo de fuerzas y resistencias que determinan las tensiones producen a su vez, antes que anulaciones, negociaciones que determinan desplazamientos y condensaciones de poderes. Lo importante de todo esto es situar a los jóvenes como parte de las tendencias emergentes y reformistas en la sociedad actual, y por eso necesariamente involucrados políticamente en el ejercicio de variadas formas de acción, resistencia y negociación con otros poderes en el mercado político.

\section{LA LEGITIMACIÓN PÚBLICA DE UNA NUEVA CONDICIÓN JUVENIL}

Para proseguir, es necesario plantear un argumento quizás arriesgado, y es que en Medellín, y en todo el mundo, se puede advertir un cambio drástico en la definición social de la condición juvenil, que en su vertiente de publificación, es decir, de visualización, reconocimiento y legitimación en la escena pública, demanda formas de participación ligadas al ejercicio de una ciudadanía específicamente juvenil, en la cual los jóvenes se empiezan a reconocer, y a la vez inciden para ser reconocidos por la sociedad, con unos derechos e intereses distintos a los de los niños, los adolescentes y los adultos.

Este cambio en la condición juvenil es un proceso de décadas que no es objeto aquí analizar, pero conviene decir que dicha condición estaba mediada exclusivamente por la afiliación de los jóvenes a instituciones que los convertían en hijos, estudiantes, revolucionarios, baluartes de la tradición o retaguardia de partidos políticos; hoy los jóvenes son además de hijos, estudiantes, etc., y más que nunca, jóve- 
nes (de una forma irrefutable, como dice mejor Benedetti). Esta desinstitucionalización de la condición juvenil ha sido una evolución compleja que supone la acción de factores de muy distinto orden, actuando en sentidos contrarios, simultáneamente y sin un desarrollo lineal.

Expongo algunos de los factores que me parecen más relevantes, sin arriesgar un mayor análisis y sin apelar a evidencia empírica de respaldo, por lo cual mantienen un status de simples opiniones.

i) La crisis de la familia tradicional y la emergencia de nuevas formas de hacer familia, que replantean y cuestionan los límites y roles de los subsistemas parentales y filiales, promoviendo nuevas reglas de interacción entre padres e hijos menos sometidas al vínculo de autoridad y sumisión.

ii) El agotamiento de las formas de movilidad y ascenso social que proporcionó la expansión de la educación secundaria y universitaria, con la consiguiente pérdida de credibilidad en estas instituciones.

iii) La pérdida de relevancia de los movimientos juveniles generados especialmente en las universidades y en la Iglesia «revolucionaria», una vez se reestructuran los marcos de significado y cultura política, que abren oportunidades políticas antes inéditas y generan actitudes más negociadoras y menos represivas en las autoridades, a la par de la falta de recambio generacional en los líderes de los movimientos estudiantiles.

iv) La disolución de identidades ligadas a la idea de nación o territorio, con el desajuste de las creencias y valores tradicionales en una nueva realidad que puso en marcha la globalización e imposibilitó el proyecto modernizador de una reproducción estable y ordenada de la cultura «nacional» en las nuevas generaciones.

v) Ligado con el factor anterior, nuevas formas de socialización con fuerte influencia de y en los medios de comunicación, que conforman una verdadera cultura juvenil, heterogénea e inconstante, en paralelo o sustitución de la socialización institucional de la familia o la escuela.

vi) Y por último, y quizás en no poco como efecto de la combinación de los factores antes enumerados, la emergencia masificada, plural e intensa de movimientos y presencias de nuevos actores sociales, entre ellos los jóvenes, que no hallaron 
lugar en el viejo formato político-institucional del país, y que presionó el diseño y sanción de un nuevo contrato social con un reconocimiento específico de la condición juvenil ligado a su participación ciudadana.

A esta lista incompleta habría que agregar dos factores que no son directamente de desinstitucionalización de la condición juvenil, pero que aportan también a este reconocimiento de los jóvenes como grupo social, el último además muy relacionado con las específicas condiciones de Medellín. De un lado, el trayecto cada vez más largo que tiene la etapa juvenil en la vida a medida que las sociedades se urbanizan. Esta transformación supone que los jóvenes durante más tiempo están afectando con sus hábitos y comportamientos, las relaciones entre jóvenes y sociedad, al tiempo que incrementan su importancia como productores y consumidores, provocando cambios en su manera de pensar la política y participar en ella. Y por otro lado, en Colombia, y probablemente más en Medellín que en otras ciudades, la aparición del «sicario» ligado al narcotráfico en los 80 , hizo visible públicamente, y revestidos como problema social, a los jóvenes, contribuyendo más decididamente que ningún otro factor, a la colectivización de un imaginario sobre los jóvenes de la ciudad, tanto local como internacionalmente: ser joven en Medellín se volvió noticia a nivel mundial.

Es importante mencionar todo esto porque el CMJ no es, digamos, un productor de ciudadanía juvenil sino una causa de esa ciudadanía todavía en vías de ganar legitimación. Sin embargo el CMJ, que surge como un reconocimiento de los adultos a esta nueva condición juvenil, sigue dependiendo todavía excesivamente de las percepciones e intereses de lo que es, con relación a los jóvenes, un «poder adulto» dominante, sea Estado, ONG o especialista en juventud.

Tal característica es, como hipótesis, un estadio anterior en el desarrollo de formas y medios institucionalizados de participación juvenil más autónomos, y que se verifican, por ejemplo, en los gobiernos escolares y en las «juventudes» de partidos políticos; en general, puedo decir que me parece constatar esta situación en aquellas instancias para la participación juvenil (y no directamente instancias de participación juvenil, sutil diferencia que convendría tener en cuenta), y que han sido el resultado de un reconocimiento de los cambios que demanda la relación jóvenes-sociedad por parte de los «poderes adultos». 


\section{POSIBILIDADES Y LIMITANTES DE LA CIUDADANÍA JUVENIL}

Continuando con lo anteriormente expuesto, me atrevo a confirmar lo que antes se insinuó, es decir, que el ejercicio de la ciudadanía más plena por parte de los jóvenes, estimulando y apoyando formas y medios propios, es más necesario para la sociedad que para los propios jóvenes, y de ahí se desprenden en buena medida la justificación de la creación de organismos con el CMJ.

La anterior afirmación merece, sin duda, una mejor explicación que facilite entender que más allá de los más elementales motivos de justicia social y solidaridad, hay razones — si se quiere, «estratégicas»-, que respaldan ampliamente las medidas públicas tendientes al fortalecimiento de las formas y medios de participación juvenil en el mercado político.

La primera, es que los jóvenes están más y mejor preparados que ningún otro grupo poblacional para participar e impulsar activamente procesos de cambio social, económico y político en una sociedad en la cual, y por primera vez en mucho tiempo, hay un consenso general para favorecer la renovación y el cambio por encima de la conservación.

La segunda, es que los jóvenes no solamente están más capacitados, con más años de estudio en promedio, ${ }^{2}$ sino que entienden mejor y más rápido lo nuevo en un mundo de cambios acelerados, donde cuenta cada vez más la plasticidad que la rigidez, tanto en habilidades como en actitudes.

Además, y en tercer lugar, si se compara a los jóvenes con otros grupos sociales, se observa que siempre están más dispuestos a

2 El mayor nivel educativo de los jóvenes se debe tomar en cuenta por su influencia para apoyar los procesos de democratización, pues Sudarsky ha comprobado en su estudio sobre Capital Social la que llama Tesis de Movilización Cognoscitiva, donde «...la creación de una democracia más activa y racional viene precedida por la expansión educativa [...] la educación tuvo el efecto de aumentar capital social [...] se puede hacer una gran elaboración a nivel de los contenidos de la educación, pero desde los estudios clásicos. [...] Lo que se sabe es que el currículum latente, es decir, el que se imprime por la asistencia misma a la escuela es el que hace la mayoría de la diferencia». John Sudarsky: El capital social en Colombia, Banco Mundial, 1999. Este hallazgo es particularmente relevante tanto para apoyar la idea de que los jóvenes pueden contribuir a generar mayor capital social por tener más años de educación como la importancia de la asistencia a la escuela para la formación de ciudadanía, a pesar de las enormes, y a veces injustas, críticas de que es objeto la institución escolar. 
comprometerse con utopías necesarias y posibles, ${ }^{3}$ siempre y cuando se les permita participar efectivamente, porque tienen menos compromisos para poder cuestionar el establishment que nosotros los adultos; dice bellamente Edgar Morin: «Al fin y al cabo, en las sociedades burocratizadas y aburguesadas, es adulto quien se conforma con vivir menos para no tener que morir tanto. Empero, el secreto de la juventud es éste: vida quiere decir arriesgarse a la muerte y furia de vivir quiere decir vivir la dificultad».

Finalmente, hay una mayor tendencia en la población joven que en otros grupos etáreos para vincularse o formar organizaciones, por lo que sin duda existe ahí una reserva que podría incrementar el capital social de nuestras sociedades en lugar de disminuirlo, lo que efectivamente sucede cuando estas organizaciones juveniles carecen de un lugar relevante en la sociedad que valorice sus aportes y les genere una saludable confianza los acuerdos que regulan la vida en común.

Pero a la par los jóvenes de Medellín enfrentan factores que limitan considerablemente sus posibilidades de ejercer más efectivamente su ciudadanía; quiero en este punto hacer una digresión que no estaba antes contemplada en el texto original de este paper, pero que en las actuales circunstancias me parece pertinente incluir.

Actualmente está vigente en Medellín un toque de queda que prohíbe la circulación por la calle de los y las jóvenes menores de edad después de las diez de la noche, como medida preventiva para disminuir los altos índices de muertes violentas que nuevamente se han incrementado en este año después de período más o menos estable de tendencia negativa. Algunos datos de la medida son las denuncias sobre distintas formas de maltrato policial a la par que se fortalece la aparente relación inequívoca entre jóvenes en las calles con rumba, alcohol, drogas, y muertes violentas.

Se pregunta uno si por esta vía no se contribuye aún más a la estigmatización social de los jóvenes como causantes principales de un fenómeno tan complejo como la violencia, más aún cuando esta medida se ha «reforzado» con el aumento del pie de fuerza militar y policial en los sitios más frecuentados por jóvenes, como ciertos luga-

3 «Los jóvenes de fin de siglo [...] aparecen en las mayorías de las encuestas como portadores de aspiraciones 'utópicamente realizables'. Libertad, justicia, valoración de la diversidad, protección de la naturaleza, son valores que concentran largamente sus tendencias» Ernesto Ottone: «Tras una utopía razonable: los jóvenes en los tiempos de la globalización». Revista Iberoamericana de Juventud $\mathrm{N}^{\circ} 4$, Madrid, 1998. 
res, parques y esquinas, con el consiguiente despliegue de acciones represivas, tan propensas a la arbitrariedad, contra una población que dispone de pocos medios propios, y menos defensores, a la hora de reclamar y exigir sus derechos, más si además de joven, se es pobre...

Este desafortunado ejemplo sirve para mostrar que los jóvenes en Medellín son a menudo señalados como un problema público, así sea indirectamente — cuando se busca aparentemente su "protección», como en el caso expuesto (y con la mejor intención, quisiera uno creer)-, en una ciudad, y en un país, con unas de las más altas tasas de homicidio en el mundo, una actividad criminal crecientemente organizada y altamente rentable, niveles elevados de corrupción, enriquecimiento ilícito e impunidad, y desconfianza casi total en la justicia, el gobierno y los partidos políticos.

De hecho muchos jóvenes calculan, desde muy pronto, los beneficios que trae actuar al margen o en contra de una sociedad que socializa inadecuadamente, no provee más protección que la que pueden ofrecer el hacer parte de distintas «roscas» o «mafias», y donde no se percibe que se compense o sancione socialmente a quienes actúan dentro o fuera del orden legal y a favor o en contra del interés público. ${ }^{4}$

A este contexto se suma una situación económica recesiva con impacto negativo en la producción, ingreso y deuda per cápita; una estructura productiva y financiera incapaz de crear la riqueza y el empleo que demanda una sociedad con altas expectativas de consumo, especialmente por parte de los propios jóvenes; y un Estado débil para hacer las reformas necesarias que hagan prevalecer el interés público sobre los intereses privados de «sindicatos» de todo tipo. ${ }^{5}$

$4 \quad$ No hago exclusiva referencia al caso más dramático de la delincuencia juvenil. Pienso, sin ir más lejos, en las acusaciones que en varias oportunidades se han hecho al propio CMJ en cuanto a su relación poco transparente con grupos políticos, antes, durante y después de elecciones (las de ellos y las de otros).

5 «Por ello, la acción sindical, en lugar de forzar al sector productivo a aumentar su productividad, se centra en el Estado debilitando aún más su acción» (Sudarsky, 1999). En similar forma operan otros grupos de poder: los empresarios, por ejemplo, privilegian la obtención de ganancias como fruto de su posición en la estructura social y no como fruto del trabajo, el ahorro la innovación o el riesgo, aprovechando su posición para incidir en políticas sociales y económicas a costa del interés público, en detrimento de un verdadero régimen de mercado y a favor de una cultura rentista que le ha supuesto al país enfrentar con una muy baja productividad y competitividad, una apertura forzada pero de todas formas necesaria. Luis Jorge Garay, DHIAL Magazine №3, 2000. 
En este escenario de crisis están instalados los jóvenes: más educados y abiertos al mundo, con mejores condiciones para liderar procesos de cambio social, político y económico, con una posición demográficamente ventajosa, ${ }^{6}$ pero en un contexto adverso para aprovechar su potencial.

En términos de ciudadanía esto se traduce, con fronteras de muy difícil demarcación, en formas más o menos anómicas de protesta o rebelión juvenil, caracterizadas por una alta dispersión individual y expresiones del tipo «sálvase quién pueda» y «quiero lo mío y lo quiero ahora», ${ }^{7}$ hasta jóvenes organizados con proyectos sociales alternativos muy creativos y socialmente rentables, pero a menudo difícilmente compatibles para participar en la actual organización política del Estado y de los partidos políticos que compiten por ocupar lugares en ella. ${ }^{8}$

\section{a) La especificidad de la acción política de los jóvenes}

¿A qué se debe esta incompatibilidad? Por lo menos en parte, se explica como resultado de especificidades radicales en las formas y contenidos de la acción política de los jóvenes, que se asumen como estrategias de legitimación social de la nueva condición juvenil. Cabe anotar que no se trata de un rasgo propio de los jóvenes, sino que es compartido por todas las culturas contra-hegemónicas que, como las

6 El informe BID «Desarrollo más allá de la economía» (1999) describe que desde el 2000 al 2030 se abre una ventana demográfica de oportunidad en Latinoamérica que consiste en una tasa de dependencia favorable (menor número de ancianos y niños por adultos laborando), ocasionada por familias más reducidas y proporciones de niños, jóvenes y adultos semejantes a la de los países desarrollados, a medida que disminuyen las tasas de natalidad y se van sumando a la fuerza laboral los niños y adolescentes de hoy, lo que significa que habrá más trabajadores pagando impuestos para educar niños y sostener jubilaciones.

7 Ricardo Becerra Laguna: «Participación política y ciudadana de los jóvenes». En Jóvenes: una evaluación del conocimiento. La investigación sobre juventud en México, 1986-1999. Tomo 2. Instituto Mexicano de la Juventud, México, 2000.

8 Sin embargo, cuando se pregunta a los jóvenes, paradójicamente mencionan altos niveles de participación en la sociedad, mucho mayores que en otros grupos etáreos. Por supuesto esta participación no tiene efectos en lo «macro», el escenario de las grandes decisiones nacionales, pero es muy eficiente en lo «micro»: el barrio, la escuela, la familia. ¿Cómo articular ambos escenarios? Es el gran reto de las instituciones como el CMJ. 
juveniles, se instauran al margen o en contra de una cultura dominante, en este caso, la de los adultos.

En otras palabras, la incompatibilidad de las alternativas de los jóvenes con el funcionamiento político adulto del Estado, primero, no son exclusivas de los jóvenes, aunque si probablemente más visibles; y segundo, sus relaciones con la cultura dominante adulta no son de oposición sino mediadas por acciones políticas que combinan -incluso racionalmente- resistencia, provocación y enmascaramiento (como si se dijera: «yo me disfrazo por un momento para acceder o ser escuchado»).

A qué especificidades me refiero concretamente, o mejor aun, qué explicación hay para éstas, para eludir un poco lo que ya hemos experimentado, todos de una forma u otra, al convivir con jóvenes en nuestras ciudades. Básicamente apuntaré dos, siendo conciente que seguramente estoy dejando por fuera causas quizás más importantes; sin embargo, me parecen éstas muy relevantes pues atañen muy directamente a los mundos de vida juveniles.

La primera tiene que ver con que mientras los tipos de acción social y política de los adultos están más dominados por criterios racionales y utilitarios, en el caso de los jóvenes, y en comparación con éstos, predominan en cambio los componentes emotivos y psicosociales:

El sentido que proporciona defender una posición que se ha hecho propia, la esperanza de lograr metas o de evitar lesiones a los intereses que se consideran valiosos por medio de la acción colectiva, [...] la seguridad cognoscitiva que resulta de compartir valores y opiniones con muchos otros, son todos fenómenos decisivos de la vida política y, particularmente sentidos y necesitados por los jóvenes. ${ }^{9}$

En segundo lugar, se verifica un cambio radical con relación a la tradición de las ideologías políticas juveniles: el devenir de los movimientos e ideologías de sentido abarcante y trascendente hacia los conflictos por intereses concretos y particulares, situados en demandas y diferencias en términos de exclusión-inclusión de las instituciones, de los barrios, de las decisiones escolares, etc.; en definitiva, el reclamo por ocupar lugares propios en la sociedad en aquello que tiene relación inmediata con sus vidas. ${ }^{10}$

9 Enzo Faletto: «La juventud como actor social en América Latina». Revista de la CEPAL No29. Santiago, 1986.

10 Recientemente la Red Juvenil, una organización de jóvenes para jóvenes, procuró la creación de un sector de organizaciones juveniles dentro de las entidades miembros de la Red Paisajoven. Más allá de los resultados de esta 
Esta conflictividad de las relaciones entre sociedad y jóvenes permite a éstos experimentar lo público por primera vez como una capacidad de «tejer una voz horizontal», como lo ha definido Hirschman: una discusión pública extendida, mediada por una motivación común de resistencia o demanda claramente formulada, con formas de organización y deliberación mínimas.

Todas éstas son, para los jóvenes, experiencias altamente significativas para adquirir puntos de referencia propios con un sentido de socialización, así como un sentido social de lo que es justo y lo que es injusto, pero a la vez dinamizan y enriquecen el corpus social: los colectivos juveniles suelen ser mucho más democráticos, comprometidos vitalmente y con una asombrosa capacidad de combinar creativamente grandes ideales con acciones pragmáticas y simbólicamente eficaces, que otros colectivos. ${ }^{11}$

b) Las oportunidades para un mayor empoderamiento juvenil

Siempre al hablar de jóvenes, y más en el tema de su acción política como ciudadanos, es posible mirar el vaso como medio vacío o medio lleno: sin embargo, en una tendencia a la devolución del poder antes concentrado en el Estado, a la sociedad, el empoderamiento de los ciudadanos y sus organizaciones van a tener un protagonismo ascendente como manifestaciones de la sociedad civil. Aquí los jóvenes pueden jugar un papel decisivo en la ampliación del espacio público, desde la esfera estatal a la esfera societal, lo que demandará que se fortalezcan como actores políticos diferenciados y se consoliden sus organizaciones propias con un mayor nivel de autonomía.

Aparentemente, al comparar en el nivel organizacional y las conquistas logradas por otros grupos sociales no dominantes, tales como las mujeres y los trabajadores asalariados, con las realizadas por las organizaciones de jóvenes, parece que estos últimos han podido conseguir muy poco a favor de sí mismos en términos materiales: basta constatar, para dar un ejemplo, que en ingresos, empleo y seguridad social, por mencionar solamente unos aspectos, hay una clara

iniciativa, todavía por definirse, es evidente que ahí se ejemplifican algunos componentes del eje de conflictividad juvenil en estos años.

11 Las características antes mencionadas son, pero en un sentido completamente inverso, las que se perciben en los partidos políticos: estructuras poco democráticas, gente poco comprometida realmente con la causa, actuaciones poco convincentes. 
discriminación en contra de los jóvenes y a favor de los adultos, y todavía más si se trata de mujeres jóvenes.

Diversos autores, como Germán Rama y Ernesto Rodríguez, entre otros, han explicado esta situación acudiendo a la transitoriedad de la condición juvenil como un factor diferenciador que influye para que las acciones corporativas de los jóvenes se guíen más por «dimensiones simbólicas», como la paz, la libertad o la justicia, y no por las «dimensiones materiales» de su misma existencia. En contraste, los grupos cuya condición vital no es transitoria, si hablamos de mujeres o trabajadores, orientan sus acciones a mejorar su situación específica, ganando derechos o fortaleciendo su posición en la sociedad.

Concluyen estos autores que ante esa transitoriedad de su condición vital, los jóvenes difícilmente pueden contar con organizaciones propias para la defensa de sus intereses, quedando dicha función en manos de instituciones especializadas, lo cual no deja de ser un handicap cuando se piensa en sociedades como la colombiana, altamente corporativizada, donde los intereses de los jóvenes pocas veces son debidamente representados desde su óptica. Es, claro está, una conclusión prácticamente irrefutable si se practica, digámoslo de esta forma, una suerte de corte longitudinal y se examina el estado actual de las organizaciones juveniles en el mercado político.

Sin embargo, quisiera decir que no tiene porqué ser así para siempre, y prospectivamente proponer otro punto de vista más optimista: actualmente se están produciendo las condiciones que facilitarán, cada vez más, la constitución y fortalecimiento de actores corporativos juveniles que puedan actuar en defensa de los intereses de las generaciones jóvenes, en virtud precisamente de la nueva condición juvenil y su paulatina legitimación social:

i) Conformación y afianzamiento durante períodos más largos de tiempo de la identidad juvenil.

ii) Desinstitucionalización de la juventud, especialmente de la escuela y la Iglesia.

iii) Cultura juvenil, con un mercado de productores y consumidores jóvenes.

iv) Reconocimiento constitucional de la condición juvenil ligado a la participación ciudadana. 
Las consecuencias para afianzar un mayor empoderamiento de los jóvenes como ciudadanos diferenciados empiezan, a mi juicio, a ser visibles y profundas:

i) Hay voluntad política y marcos de apoyo jurídico por medio de leyes, políticas, programas y proyectos cada vez más específicos. ${ }^{12}$

ii) Se hacen esfuerzos por mejorar el acceso de los jóvenes al conocimiento, información y práctica de derechos, tanto universales como propios de su condición juvenil. ${ }^{13}$

iii) Se desarrollan y fortalecen mecanismos paralelos de participación en la toma de decisiones por parte de los jóvenes, que se capacitan e intervienen en la formulación de políticas y el diseño de programas.

Todo lo expuesto anteriormente representa una oportunidad nada despreciable para las organizaciones juveniles conformadas en sociedades donde priman las acciones corporativas sobre el interés general, y en las cuales tradicionalmente han sido los adultos quienes han asumido exclusivamente la tarea política de proteger los derechos de los jóvenes, la mayor parte de las veces con enfoques marcadamente paternalistas, asistencialistas y clientelistas.

\section{LOS OBSTÁCULOS PARA AMPLIAR EL EMPODERAMIENTO DE LOS JÓVENES}

A pesar de lo anterior, existen obstáculos específicos que es preciso remover para una acción más efectiva de las acciones corporativas juveniles en favor de una ciudadanía juvenil con mayor poder democrático:

i) Las leyes y mecanismos específicos mediante los cuales los jóvenes, particularmente los que tienen entre 18 y 25 años, pueden ejercer efectivamente su participación ciudadana están todavía por

12 Basta constatar el auge de una institucionalidad gubernamental especial para el tema juvenil, desarrollos legislativos y políticas integrales, así como la creciente inversión de distintos organismos multilaterales y de cooperación para el desarrollo en programas dirigidos a jóvenes.

13 Al respecto hay que constatar el avance que ha tenido la Carta Iberoamericana de los Derechos de Adolescentes y Jóvenes, impulsada por la oIJ y la UNESCO. 
consolidar y afinar; en tal sentido, el estatuto de ciudadanía para los jóvenes todavía está por normatizar, habida cuenta de que las disposiciones legislativas vigentes que rigen el acceso de los jóvenes a los derechos políticos a menudo están desajustadas o contradicen los vacíos, restricciones y responsabilidades en aspectos penales, laborales o de protección y seguridad social.

ii) La pretensión de las políticas sociales de homogeneizar, en la mejor tradición «modernizante», a la juventud como una sola, y por lo tanto sus intereses y necesidades. Al respecto hay dos dificultades de base: la poca investigación sobre los reales y específicos intereses de los jóvenes según condiciones particulares de vida, en contradicción con la abundancia de interpretaciones y «modelos» de jóvenes con muy pocos datos de respaldo, ${ }^{14}$ y la concepción «ortopédica» con que son enfocadas las políticas sociales en general, y que en el caso de los jóvenes se concentran más en resolver «sus problemas» de inserción que en las potencialidades de los jóvenes para resolver en los problemas de la sociedad que los excluye como grupo.

iii) Resistencias de los sectores adultos, con una posición política hegemónica, en relación con los jóvenes, como poder político emergente. El gran interrogante es cómo la sociedad adulta puede abrir reales opciones de acceso al poder democrático para los jóvenes cuando se carece de movimientos juveniles coordinados, la no identificación de los jóvenes con los partidos políticos y la debilidad del tema juventud como asunto estratégico en las agendas públicas, dominadas totalmente por sectores adultos.

iv) Parte importante de esta resistencia adulta es la dificultad para reconocer nuevas formas de organización social entre los jóvenes, y lo que es principal, darles la oportunidad a estas organizaciones de construir poder político, lo que pasa, sin duda alguna, por una transferencia efectiva de recursos legales, materiales, económicos y, desde luego, formativos. ${ }^{15}$

14 Habría que pensar en muchos y variados grupos de jóvenes: hombres y mujeres; adolescentes y jóvenes; estudiantes y no estudiantes; trabajadores y desempleados, etc., por decir muy poco.

15 Y digo desde luego porque, desde la lógica modernizante de los adultos, pareciera que la formación es lo único importante, entendida como «aculturación» (todos los cuentos sobre la «calificación de la participación»). Eso quiere decir que se piensa, por ejemplo, que basta con formarlos en «democracia» para que vayan y se hagan ciudadanos, o en diseño de proyectos, para que tengan proyectos propios. 
v) Los jóvenes y sus organizaciones son fuertes en los escenarios de microparticipación, muy cercanos a los asuntos que afectan su entorno inmediato, pero situados en la periferia del sistema de decisiones políticas y económicas. Esta situación, además avalada por muy conocidos expertos, ${ }^{16}$ idealiza la interacción solidaria del pequeño grupo y cierta virtud comunitarista y juventocéntrica que, sin embargo, los desarticula del mundo adulto en que se definen, finalmente, sus reales posibilidades de ciudadanía.

vi) En relación con lo anterior, cooptación de jóvenes en las organizaciones adultas para funciones de tipo «carga-ladrillos», en lugar de verdaderas formas de participación: ${ }^{17}$ raras veces tiene poder más allá de las actividades y objetivos de los proyectos que formulan, si es que lo hacen. Pero no tienen acceso a los recursos para su ejecución, ni negocian los presupuestos, ni están en los lugares de decisión.

vii) Carencia de información completa y comprensible para los jóvenes sobre alternativas e implicaciones de decisiones públicas en materia económica y política. Por ejemplo, ninguna organización juvenil ha promovido un debate serio sobre las consecuencias positivas de la liberalización del mercado laboral para los jóvenes, las consecuencias de las reformas pensionales para las futuras generaciones. ${ }^{18}$

viii) Formalización excesiva de estructuras de participación juvenil e imposición de requisitos «adultos» para la operación de las organizaciones juveniles, bajo la idea de formación, control y supervisión técnica, que termina siendo una restricción política a la autonomía juvenil y a sus capacidades de actuación efectiva.

\section{EL CMJ EN ESTE CONTEXTO DE OPORTUNIDADES Y OBSTÁCULOS}

Por razones que no son objeto de esta presentación, pero a las

16 Ver la conferencia de Luis Carlos Restrepo sobre el rol social del joven de sectores populares, donde acríticamente se defiende la participación juvenil como algo únicamente ligado y efectivo en el entorno inmediato. No es que no sea cierto, pero la cuestión es cómo hacer que deje de ser así...

17 Debe decirse que muchas veces estas formas son replicadas por líderes juveniles en sus organizaciones.

18 La única organización de jóvenes que en forma sistemática ha venido adelantando campañas de información a jóvenes sobre un tema que los afecta sustancialmente y promoviendo posiciones de este grupo social frente al tema, es la Red Juvenil a través de la Objeción de Conciencia. 
que muy indirectamente he hecho alusión, es crucial para la sociedad actual hacer avanzar el proceso de ciudadanización juvenil, que en medio de sus particulares condiciones de consolidación, tiene un papel importante en el impulso a los cambios que requiere la sociedad. En tal sentido es posible que las organizaciones juveniles puedan aumentar considerablemente su capital en el mercado político, en un futuro relativamente próximo.

Sin embargo, es necesario remover los obstáculos específicos ya mencionados, además de otros que quizás sean más responsabilidad de instancias especializadas, que conjuntamente restringen las posibilidades de un ejercicio ciudadano más efectivo de los jóvenes. Y digo específicos insistiendo en que no estoy haciendo referencia a las necesidades de educación e inserción laboral de los jóvenes, que también son fundamentales, sino a únicamente a los impedimentos que son más de tipo político, por llamarlos de alguna manera.

Creo que la remoción de estos obstáculos es, con mucho, el campo de actuación para el CMJ pero desde una posición política de representación y promoción (advocacy) de los intereses de los jóvenes ante el gobierno municipal y la sociedad, en una relación de igual a igual, y no como asesores y consultores de la Alcaldía, que es un rol técnico y subordinado, ${ }^{19}$ como el que tiene, por ejemplo, Paisajoven o la Oficina de la Juventud.

Igualmente existen ya instituciones que procuran mejorar la educación de los jóvenes o sus ingresos, como efecto del acceso al mercado laboral en condiciones más competitivas; también hay otras, públicas y privadas, que se ocupan de la defensa de sus derechos o les ayudan para que desarrollen proyectos de vida personales y colectivos. Ninguna de las anteriores puede, sin embargo, asumir la representación formal de los jóvenes ante otros poderes igualmente instituidos para representar públicamente a otros grupos de intereses. Indudablemente este poder, siendo todavía algo más nominal que efectivamente real, ha sido cuestionado tanto por su énfasis en la promoción de la organización de los jóvenes como en la representatividad del CMJ.

En torno a las estrategias para aumentar la participación juvenil en la sociedad, y si éstas deben dirigirse a las organizaciones juveniles o no, se ha discutido extensamente y me excuso por faltar a la

19 Recuerdo que en los viajes de Gulliver, en el reino de Liliput, únicamente los súbditos más éticamente probos, los más buenos, eran quienes ocupaban cargos en el gobierno, no así los más inteligentes o sabios. 
enumeración completa de las diferentes posiciones, que sintetizo en los que, hasta ahora, me parecen los únicos argumentos realmente incuestionables: (i) que todos los jóvenes se organizan; (ii) que no todos los jóvenes están organizados; (iii) que finalmente todo depende de que entendemos por organización. Mi posición al respecto, muy elemental, es la siguiente.

i) Hay muchas y variadas formas de organización social, y las organizaciones juveniles destacan por su multiplicidad. Sin embargo, es casi un imperativo de la condición juvenil, por decirlo de otra manera, está en su naturaleza, formar grupos e identificarse muy clara y conscientemente por su pertenencia a estos grupos.

ii) Las agrupaciones sociales de cualquier tipo sirven para aumentar la fuerza y el poder de los individuos ante otros grupos o individuos más poderosos: son lugares de acumulación de demandas, movilización de recursos y gestión de intereses.

iii) El capital social se incrementa, entre otros medios, por la vinculación de los individuos con organizaciones sociales diferentes a la familia y a la Iglesia.

iv) No necesariamente todas las organizaciones juveniles, o si se prefiere, los agrupamientos juveniles, deben instituirse formalmente para hacer cosas y ser eficientes.

v) Debe coexistir un adecuado balance entre organizaciones juveniles con condiciones de mayor perdurabilidad y formalización administrativa y jurídica, ${ }^{20}$ vinculadas con, digamos, «intereses de clase» juvenil, junto con otras más efímeras y ligeras, asociadas a una acción en el entorno inmediato y para desarrollar intereses más particulares. $^{21}$

vi) Las políticas públicas de juventud deben apoyar e incenti-

20 Como por ejemplo la Red Juvenil, una ONG de jóvenes para jóvenes, y el mismo CMJ.

21 En este punto me pregunto por el lugar de organizaciones como la Pastoral Juvenil y los Scouts. Son para mí ONG’s de adultos que de diferente forma dirigen su atención a los jóvenes casi exclusivamente. Siendo así, son muy válidas y necesarias, pero es obvio que en estas organizaciones es relativamente inferior la autonomía de los jóvenes y está bastante restringida su participación en las grandes decisiones de la institución. Es un caso diferente el de las organizaciones de estudiantes dentro de las escuelas o universidades: ahí es factible desarrollar mayores niveles de autonomía, puesto que se configura como una organización aparte dentro de la organización «adulta» y algunas veces alcanzando altos grados de influencia en las decisiones colectivas de la institución. 
var decididamente que los jóvenes creen organizaciones propias, estimulando proyectos colectivos formulados a partir de la convergencia de sus propios intereses y demandas, facilitando no tanto que se formalicen y perduren en el tiempo, sino que efectivamente realicen lo que se han propuesto con altos niveles de autonomía y responsabilidad sobre el manejo de recursos.

vii) En conclusión, y tal como está planteado, no solamente es inoficioso el debate sobre la prevalencia de la organización juvenil en las políticas de juventud como agente no sólo receptor, sino dinamizador de las políticas y perjudicial porque por la pretensión de parecer «muy democráticos» se incurre en debilitar la sociedad civil como necesaria contraparte del Estado y del mercado.

Esta discusión, más o menos adornada, ha incidido también en los cuestionamientos a la representatividad del CMJ. Indudablemente el CMJ, hoy en día, no representa a casi ningún joven de la ciudad, en un país donde el problema de la representatividad es un permanente desafío para la construcción de una gobernabilidad democrática. Sobre este punto en particular, mi posición ha sido que el CMJ no solamente deberá ganarse la legitimidad de esta representación — que por otro lado, mirando bien nadie más podría tener, pues es una institución a la que se accede por mecanismos y procedimientos de calificación pública-, sino actuar en consecuencia, es decir, como si efectivamente lo fuera, justamente para conseguir esa legitimidad y afianzarla.

Bien podría uno decir que simplemente cada joven se represente a sí mismo en la sociedad, en una forma de «democracia» tan extrema e idealista cuyas evidentes limitaciones prácticas ni siquiera vale la pena discutir, pero que además, sin duda, tributan a las posturas individualistas del «sálvese quién pueda», que tanto erosionan el capital social. Muy por el contrario, y aprovechando el altísimo nivel de participación que tiene los jóvenes en organizaciones de todo tipo, un Consejo Municipal de Juventud es una oportunidad de agregar, canalizar y movilizar demandas de jóvenes para aumentar el poder democrático de los ciudadanos juveniles.

En tal sentido la acción del CMJ debe encaminarse a remover los obstáculos que limitan el pleno ejercicio de la ciudadanía en la especificidad de la condición juvenil, apoyando la construcción de consensos entre los jóvenes, y capitalizando este consenso en el mercado político. Estratégicamente sus principales aliados deben ser las organizaciones juveniles, o más aún, la visión de los jóvenes como 
potencialmente capaces de organizarse y actuar articuladamente en su beneficio. En cambio, el peor negocio político del CMJ ha sido competir con las organizaciones juveniles, como si fuese una de ellas, pretendiendo legitimarse a través de ejecutar proyectos para «darle a los jóvenes», en lugar de apoyar que sean las propias organizaciones de jóvenes las que consigan, con base en el incremento de su capital político, pasar de una posición mendicante a una de ciudadano.

\section{IMPACTO DEL CMJ EN LA AGENDA PÚBLICA: UNAS PROPUESTAS PARA LA ACCIÓN}

Consecuente con esta función básica que tendría el CMJ de ayudar a remover los obstáculos que afectan la ciudadanía juvenil y limitan su participación como actores políticos, actuando un rol político de representación y promoción de los intereses juveniles en la sociedad, quiero hacer unas propuestas concretas de acción que el CMJ podría encarar. En principio, y como derrotero general de orientación, el CMJ debe alinearse decididamente con los tendencias más reformistas de la sociedad, lo que significa tomar en cuenta, al menos, las ya enumerados y estar atento a identificar otras nuevas, bajo la premisa de que estas tendencias son potencialmente benéficas para mejorar la situación de los jóvenes en la sociedad. Más específicamente, creo que las siguientes líneas de acción contribuirían a consolidar su función institucional.

i) Establecimiento de redes y alianzas con organizaciones juveniles, partiendo de actividades significativas de reconocimiento mutuo, identificación de problemáticas y recursos, planes de acción comunes y mecanismos de comunicación efectivos.

ii) Fomentar el establecimiento y/o mejoramiento de fondos de apoyo a las iniciativas de jóvenes, formas de redistribución del ingreso y servicios especializados que beneficien directamente a jóvenes.

iii) Contratación y divulgación de encuestas sobre opiniones de los jóvenes acerca de asuntos públicos que los afectan, así como el debate de estos resultados en escenarios como el concejo de la ciudad.

iv) Apoyo a la tematización crítica de las discriminaciones sociales, políticas y económicas contra los jóvenes en la sociedad, promoviendo campañas y encuentros para incidir en la opinión pública, más específicamente en la de adultos altamente significativos para los jóvenes, como padres de familia, maestros y empresarios. ${ }^{22}$

22 Y no propiamente los técnicos y especialistas de juventud, a los que no hay 
v) Funcionar como una especie de ombudsman de los jóvenes, identificando y denunciando públicamente hechos y situaciones que contra sus derechos, así canalizando reclamos de los jóvenes y apoyando su debida atención por parte de los organismos especializados.

vi) Vincularse a iniciativas de descentralización de servicios y oportunidades para jóvenes, apoyando las organizaciones de jóvenes para que incrementen su participación en éstos; la planeación operativa anual de inversiones por comunas y zonas, las experiencias piloto de algunos barrios en integración de servicios para jóvenes, los centros de información juvenil descentralizados, y las alcaldías menores que propone el nuevo alcalde, son excelentes oportunidades que el CMJ debería aprovechar.

vii) En la misma tónica, el CMJ debe fortalecer su relación con las Juntas de Acción Comunal para promover una mayor participación de los jóvenes en estas organizaciones; una forma de empezar sería que el CMJ promueva la realización de un estudio sobre la participación de los jóvenes en estas organizaciones. ${ }^{23}$

Pienso que estas acciones aumentarían el impacto del CMJ en la agenda pública, pero sin duda se va a requerir que cambien su orientación, demasiado preocupada por alcanzar el status de «asesores y consultores» del Estado, por otra más encaminada a la mediación política de los intereses juveniles. ¿Qué quiere decir esto? Que en lugar de prepararse para ser «buenos burócratas», algo que, por ejemplo, debe hacer uno, aprendiendo a hacer proyectos, elaborar presupuestos y llenar informes de seguimiento, el CMJ debe dedicarse con más énfasis, sin decir que deberían saber algo de lo otro, a ser muy buenos comunicadores, a estimular y saber aprovechar la participación de los jóvenes, y a manejar con solvencia un panorama de las necesidades e intereses de los jóvenes, así como de la oferta, en calidad y cantidad, de beneficios, oportunidades y servicios disponibles para este grupo etáreo.

necesidad de sensibilizar. Una cosa es evidente: hasta que el tema juventud no sea socialmente relevante, seguirá ocupando un lugar secundario y poco satisfactorio en las políticas sociales del gobierno.

23 Hay una investigación más o menos reciente sobre participación en las Juntas de Acción Comunal realizada por la Secretaría de Desarrollo Comunitario que podría dar importantes pistas sobre el asunto. 


\section{EL FORTALECIMIENTO INSTITUCIONAL DEL CMJ COMO REQUISITO INDISPENSABLE}

¿Qué tipo de cambios necesitará el CMJ en cuanto institución para acompañar las acciones antes recomendadas? Obviamente estas reformas no serán instantáneas: lo importante es que sean discutidas, concertadas, planeados y respaldadas desde muchos sectores. Si no se procede de esta manera, sencillamente no estaremos siendo racionales y volveremos a exigir demasiado a una institución que políticamente es muy poco eficiente, generando y acumulando más frustraciones para todos. Serían asuntos claves impulsar cambios en los siguientes aspectos.

\section{a) Reformar el estatuto legal del CMJ}

Es prioritario precisar y mejorar el estatuto legal del CMJ, que hace prevalecer las funciones técnicas (de asesoría y consultoría), sobre las políticas (de representación). Yo no voy a hacer recomendaciones puntuales puesto que desconozco en gran parte los aspectos jurídicos y los mecanismos legales para hacerlo, fuera de que con frecuencia, y en este punto, siempre surgen controversias que terminan siendo más de forma, que de fondo. Y el fondo es que a pesar de los intrincados caminos de nuestro Derecho, siempre se puede inventar algo mejor, ${ }^{24}$ y mejor para el CMJ significa dotarse de más autonomía y peso real dentro del sistema de tomas de decisión del gobierno municipal.

Simultáneamente es necesario que se revisen los estatutos del CMJ, básicamente para prever normas y mecanismos que garanticen una mayor responsabilidad pública (accountability) de este organismo, que le obliguen a una actuación visible, es decir, verdaderamente pública, y refuercen su neutralidad política. ${ }^{25}$

24 «La creación de la política tiene lugar debido a que la institución dada de la sociedad es puesta en duda como tal y en sus diferentes aspectos y dimensiones» dice Cornelius Castoriadis. Interpreto simplemente que así como se inventó el CMJ puede siempre ser reinventado, al igual que sus relaciones con otros actores, y las reglas que formalizan esa relación. Consecuentemente el CMJ es una oportunidad para que el Estado experimente con nuevas formas de mecanismo electorales, buscando una mejor adaptación a las condiciones específicas de los jóvenes, extrayendo aprendizajes que luego pueden ser útiles en otras elecciones. El mensaje es que no hay razón para repetir siempre lo mismo.

25 Si bien es casi inevitable que dentro del CMJ haya un nivel de injerencia de 
También sugeriría considerarse ampliar el período de dos años en que los consejeros ejercen sus funciones: además del argumento de los costos que organizar elecciones, las verdaderas posibilidades de realizar cosas importantes en un tiempo tan corto para jóvenes cuya participación es voluntaria y, por lo tanto, no tienen dedicación de tiempo completo a sus actividades como consejeros, son mínimas y no son consistentes con la realidad.

De otro lado, pensar en períodos siquiera de un año más, incrementaría el acumulado de vivencias y aprendizajes que los consejeros tiene oportunidad de agenciar y que les da grandes posibilidades de continuar en la política, contribuyendo así a la renovación de la misma. Éste es uno de los principales valores agregados del primer CMJ: su aporte a la construcción de élites con una experiencia distinta del quehacer político. Sería necesario darles la oportunidad a los nuevos consejeros, muchos dependientes de partidos políticos tradicionales, de que conozcan y se relacionen con sectores más progresistas de la ciudad y alternativas distintas de pensamiento público.

Finalmente hay que hacer una profunda revisión de la forma en que actualmente es elegido y conformado el CMJ, en concreto:

i) Revisar la categoría de jóvenes «independientes» dentro del CMJ, por sus efectos sobre las posibilidades de fortalecer o debilitar movimientos y organizaciones juveniles, y evitar que aprovechando esta figura tan poco clara se facilite la entrada subrepticia de intereses clientelistas que aprovechan esta «independencia» para actuar con impunidad sin despertar las sospechas de una población que, en general, tiene muy mala opinión de los partidos políticos. ${ }^{26}$

ii) Volver a las elecciones de consejeros en representación de los jóvenes de cada comuna y corregimiento, en lugar de la elección de consejeros en representación de «toda la ciudad», ya que de esta

los partidos políticos, lo que debe garantizarse es que como institución el CMJ sea políticamente neutral en cuanto a no favorecer a ningún partido político en contra de otro.

26 Ante los orígenes que tuvo esta decisión, aparentemente basada en el riesgo de que organizaciones juveniles muy poderosas coparan el espacio abierto por el CMJ, lo que nunca ha pasado en la realidad, podría hacerse una diferencia entre las organizaciones verdaderamente juveniles, de las organizaciones adultas que tienen un sector juvenil, estableciendo para cada clase criterios especiales para la inscripción de candidatos y circunscripciones electorales distintas. 
forma se diluye la responsabilidad de cada consejero y les resta posibilidades de construir las relaciones cercanas que en el caso de los jóvenes hacen parte esencial de su acción política. ${ }^{27}$

b) Sacar el CMJ de la Oficina de la Juventud o sacar la Oficina de la Juventud del CMJ

Desde su origen el CMJ estuvo en exceso muy ligado a la acción del Estado, y en particular a la Oficina de la Juventud (OJ), generándose comprensibles recelos y competencias entre las instituciones que conllevaron a distorsiones del rol de cada una, pero que también contribuyendo negativamente al aislamiento del CMJ de los movimientos juveniles de base. Si bien el anterior consiguió romper con esa situación, después de casi dos años, el actual parece otra vez «enredado» en problemas de comunicación con la OJ.

Efectivamente en la actualidad el CMJ sigue siendo excesivamente dependiente de la Oficina de la Juventud. Esta última facilita el manejo administrativo de los recursos que se asignan al CMJ, ya que por ahora no hay otra posibilidad, puesto que el CMJ no tiene autonomía presupuestal. El ejercicio de esta actividad por parte de la OJ requiere el cumplimiento por parte del CMJ de unos requisitos exigibles para poder justificar el gasto ante los organismos de control interno.

En la práctica esta situación, por demás perfectamente comprensible y necesaria, provoca confusiones acerca de la autonomía del CMJ, injerencias indebidas en asuntos de tipo administrativo u organizacional, y desconfianzas mutuas que empañan las buenas intenciones de una y otra institución, afectan la comunicación entre ellas y, peor todavía, aleja a otros actores que no perciben claridad en los propósitos de ambas instituciones frente a su relación. Sería muy saludable para ambas instituciones si la OJ evitase al máximo cualquier otra

27 Una breve digresión. Políticamente el joven procede con pequeñas concertaciones en los escenarios de microparticipación: la familia, la escuela, el barrio, los amigos de la barra. Es este acumulado de interacciones, el que debe ser eficazmente movilizado y agregado a otros por medio de las organizaciones juveniles, y en especial por el CMJ. Por esto es nefasto para el CMJ que se hayan efectuado elecciones de jóvenes "por toda la ciudad», un claro ejemplo de la aplicación de la lógica adulta de elecciones de consejos municipales, combinado con el desconocimiento de la vida cotidiana juvenil. De esta manera lo que se ha reforzado es el aislamiento de los consejeros de sus bases de legitimación política y donde su acción debe ser más visible y concreta. 
forma de «control» distinta sobre el CMJ, básicamente dejando el acompañamiento de esta organización en organizaciones no gubernamentales y consultores especializados, y promoviendo ejercicios de concertación con otros actores sociales que le faciliten al CMJ superar su aislamiento.

\section{c) Cualificar la acción del CMJ}

El CMJ debe contar con asesores permanentes en materias que son de su competencia o en procesos organizativos requeridos para su mejor desempeño, en lugar de desgastarse pretendiendo aprenderlo y/o hacerlo todo por sí mismo. Estas asesorías deberían ser elegidas según una evaluación de necesidades y una calificación de méritos de los asesores que se propongan, actividades que deben contar con la participación del propio CMJ. No soy partidario de asesores asignados por la Oficina de la Juventud u otro ente estatal, aunque sea con muy buena intención y personal muy calificado.

Los anteriores consejeros, por lo menos algunos, deberían relacionarse más activamente con el CMJ actual, quizás en forma de una especie de comité asesor con funciones y responsabilidades muy bien delimitadas, que permita tanto el aprovechamiento de la experiencia política acumulada por estos jóvenes en cinco años, como mantener cerca del proceso de participación juvenil a jóvenes muy cualificados que puedan ser la base de una élite en la renovación de las formas de hacer política en la ciudad.

\section{d) Posicionar estratégicamente el CMJ} en la política municipal de juventud

Dentro de la política de juventud, el CMJ debe preocuparse por definir ventajosamente su rol en relación con el sistema municipal de juventud, considerando su función clave de representación y promoción de los intereses juveniles. Esto significa que deberá conseguir posiciones estratégicas dentro de las instancias de coordinación y articulación política del sistema, pero sin descuidar para nada su relación con las organizaciones juveniles de base.

e) Apoyar el desarrollo organizacional del CMJ

Todos estos cambios deben enmarcarse en un proceso de rein- 
geniería de la organización dirigido a mejorar la relación del organismo con sus ciudadanos-clientes (los jóvenes). En tal sentido debe replantear absolutamente sus planes de trabajo, estructura de funcionamiento, revisar y recomponer reglas, mejorar la comunicación interna y externa, establecer adecuados sistemas de incentivos y motivación para sus integrantes, y un largo etcétera, todo esto para diseñar un CMJ a la medida de sus responsabilidades, pero también dentro de sus posibilidades actuales, que son, con mucho, la de sus propios integrantes para llevarlos a cabo.

MEDELLÍN (COLOMBIA), JUNIO DEL 2002 